\title{
An unheated permeation device for calibrating atmospheric VOC measurements
}

\author{
J. Brito ${ }^{1,2}$ and A. Zahn ${ }^{1}$ \\ ${ }^{1}$ Institute for Meteorology and Climate Research, Karlsruhe Institute of Technology (KIT), Germany \\ ${ }^{2}$ now at: Institute of Physics, University of Sao Paulo, Brasil
}

Received: 5 April 2011 - Published in Atmos. Meas. Tech. Discuss.: 17 May 2011

Revised: 27 September 2011 - Accepted: 28 September 2011 - Published: 13 October 2011

\begin{abstract}
The development of an unpowered permeation device for continuous calibration of in-situ instruments measuring atmospheric volatile organic compounds (VOCs) is described. Being lightweight and compact, and containing only negligible amounts of chemicals, the device is especially suited for field use such as on board aircraft. Its speciality is to maintain the permeation process in thermal equilibrium, so that the instantaneous permeation rate can be ascribed to a simple temperature measurement. This equilibrium state is maintained by a combination of three features: (i) a thin PTFE membrane as permeation medium which guarantees short stabilization times, (ii) a water bath as heat buffer, and (iii) a vacuum-panel based insulation, in which features (ii) and (iii) minimize temperature drifts to $\sim 30 \mathrm{mK} \mathrm{h}^{-1}$ per Kelvin temperature difference to the environment. The respective uncertainty of the permeation rate due to thermal non-equilibrium is kept below $1 \%$. An extensive theory part details the major permeation processes of gases through porous polymers, being Fick's diffusion, Knudsen flow, and viscous flow. Both the measured stabilization time and the measured temperature dependence of the permeation rate independently indicate that the permeation can be described by a viscous flow model, where diffusion of the gas molecules in large pores (having a diameter of $>0.05 \mu \mathrm{m}$ ) dominates.
\end{abstract}

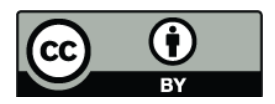

Correspondence to: A. Zahn (andreas.zahn@kit.edu)

\section{Introduction}

Volatile organic compounds (VOCs) such as carbonyls, alcohols, organic nitrates, organic pernitrates, and peroxides are extremely relevant for the chemical processing in the atmosphere (Jenkin et al., 1997; Williams, 2004). They serve as fuel for the photochemical production of ozone (Atkinson, 2000), contribute significantly to the organic components of aerosol particles (Odum et al., 1996, 1997; Jimenez et al., 2009; de Gouw et al., 2011), and produce free radicals influencing the oxidizing capacity of the atmosphere (Singh et al., 1995; Wennberg et al., 1998). However, the quantitative knowledge of their atmospheric budget, i.e. sources and sinks as well as their spatial and temporal variation in the atmosphere is still limited (Pozzer et al., 2010). Reliable analytical tools for their accurate measurement in the atmosphere are a prerequisite for a better quantitative understanding of the controlling processes. That is, an accurate and reliable calibration system is an essential requirement for state-of-the-art VOC instruments. Calibration systems for in-situ instruments rely either on static or dynamic methods (Namiesnik, 1984).

Static methods are based on mixtures of calibration gases stored in closed housings such as high-pressurized gas cylinders with previous wall treatment (Rhoderick and Miller, 1993; Apel et al., 1994, 1998). These calibration cylinders are robust and usually contain a suite of species. The concentrations in the bottle are typically $1 \mathrm{ppmv}$ and their uncertainties usually $5-15 \%$ depending on compound and preparation method (Apel et al., 1998; Rappenglück et al., 2006; Wyche et al., 2007). Despite being a suitable method for calibrating a large number of species, a number of loss processes

Published by Copernicus Publications on behalf of the European Geosciences Union. 
may occur, especially in case of reactive/polar compounds, e.g. oxygenated compounds including some aldehydes, alcohols and specially acids (Barratt, 1981; Rappenglück et al., 2006). That is, these VOCs may degrade in cylinders over time and in addition may not quantitatively be extracted due to adsorption on the cylinder surface. Further uncertainty may be generated when diluting the calibration gas to the desired concentration, which is mostly done using mass flow controllers, pressure controllers, and/or critical orifices.

In dynamic methods a continuous flow of the relevant analyte is diluted into a carrier gas stream. Dynamic methods most commonly used are mixing of gas streams, diffusion methods, capillary injection, syringe injection and permeation devices (Namiesnik, 1984; Jardine et al., 2010; Isaacman, 2011). Diffusion methods and permeation devices are extensively used for the calibration of instruments measuring VOCs in low concentrations (Williams, 1976; Gautrois and Koppmann, 1999; Washenfelder et al., 2003; Jost, 2004; Thompson and Perry, 2009; Veres et al., 2010). These methods are suitable for a large range $(>500)$ of species including reactive/polar compounds, unlike static methods. However, compounds that have high vapour pressures and are in the gas phase at room temperature (such as all alkanes and low number $(\leq \mathrm{C} 4)$ alkenes $)$ are not usuable for permeation devices.

For atmospheric in-situ measurements onboard aircraft, permeation devices have several advantages over highpressurized gas cylinders. These are light weight, small volume, and the ability to meet safety clearance due to the lack of overpressure and the use of only very small amounts of chemicals. However, power loss during transport or before take-off due to fuelling of the aircraft can push the permeation system from equilibrium and thus prevents accurate calibration until equilibrium is once again reached.

In this paper we describe a new calibration system developed for calibrating our airborne proton transfer reaction mass spectrometers (PTR-MS). Using water as heat buffer, combined with vacuum-panel based insulation and a fast stabilizing permeation membrane, we have conceived a calibration system that has the portability and robustness of regular permeation sources, without the requirement for temperature stabilization. Its actual permeation rate is solely a function of temperature which can be accurately measured. With these characteristics, the presented calibration source is especially suitable for field applications, e.g. on board aircraft.

\section{Permeation devices}

Permeation methods have been developed in the 1960s (O'Keeffe and Ortman, 1966) as standard for trace gas analysis and have been used extensively since. They usually comprise a short polymer tube sealed at both ends by glass plugs and filled with the analyte of interest. The analyte vapour dissolutes into the polymer, diffuses through it, and finally mixes into the sample gas stream. For most analytes, the permeation rate is strongly dependent on temperature. A common rule of thumb states that for every degree Celsius of temperature increase, the permeation rate increases by 5$10 \%$ (VICI Metronics, 2004). This relationship holds because the permeation rate $(\mathrm{P})$ usually shows an Arrheniuslike behaviour (Mitchell, 2000; Washenfelder et al., 2003; Tumbiolo et al., 2005):

$P=P_{0} \cdot \exp \left(-\frac{E}{R \cdot T}\right)$,

where $P_{0}$ is a constant (unit: $\mathrm{ng} \mathrm{s}^{-1}$ ), $E$ the activation energy, $R$ the gas constant and $T$ the absolute temperature.

Thus, in order to maintain quantified and constant permeation rates, permeation devices are kept in temperature controlled conditions before and during their use. The time until a permeation device reaches an equilibrated state, the socalled stabilization time, typically ranges from hours to days (Williams, 1976).

In the following Sect. 3 an introduction to the theory that describes the transport of gases through polymers is given. Special attention will be given on its temperature dependence and stabilization time.

\section{Permeation: a theoretical description}

\subsection{Gas transport through polymers}

As initially described by Thomas Graham, the transport of small molecules through a polymer membrane occurs due to random molecular motion of individual molecules (Pandey and Chauhan, 2001). The driving force behind the transport is the concentration difference across the polymer membrane.

At steady state, this transport can be described in terms of Fick's first law of diffusion, according to which the flux $\mathrm{J}$ (in direction of the concentration gradient) is proportional to the concentration gradient $\partial c / \partial x$ and the diffusion coefficient $D$ (unit: $\mathrm{m}^{2} \mathrm{~s}^{-1}$ ):

$J=-D \cdot \frac{\partial c}{\partial x}$,

and in the integrated form:

$J=D \cdot \frac{c_{2}-c_{1}}{l}$

with $l$ the membrane thickness and $c_{1}, c_{2}$ the concentrations below and above the membrane. In ideal case, the analyte concentration c dissolved in the polymer will be given according to Henry's law:

$c=S \cdot p$ 
with $S$ the solubility and $p$ the pressure. Combining Eqs. (3) and (4) gives the well-known permeation equation (Klopffer and Flaconneche, 2001):

$J=D \cdot S \cdot \frac{p_{2}-p_{1}}{l}$

where $p_{1}$ and $p_{2}$ are the ambient partial pressures on the two sides of the membrane. The product $D \cdot S$ is intrinsic to the membrane material and is defined as the permeability coefficient B:

$J=\mathrm{B} \cdot \frac{p_{2}-p_{1}}{l}$.

This approach, usually known as solution diffusion model (Stannett, 1978; Stern and Trohalaki, 1990), only works for special membrane materials, namely homogeneous nonporous polymers. However, polymers typically used in permeation devices (see below) are porous. Here, adsorption in the polymer and hopping of molecules from pore to pore occur as well, which usually dominate over permeation due to solution-diffusion transport.

The most prominent polymer used in permeation devices is polytetrafluoroethylene (PTFE). PTFE is a porous semicrystalline material (Xiuli et al., 2003; Yi-Yan et al., 1980; Mohamed and Abdel-Hady, 2007), i.e. it is formed of amorphous and crystalline regions. Already $50 \mathrm{yr}$ ago, Michaels and Bixler (1961a,b) showed that sorption and diffusion in semicrystalline polymers take place exclusively in the amorphous regions. The crystalline zones however act as impermeable barriers for diffusion.

To describe the transport in porous materials, the gas transport is parametrized either as viscous (or Poiseuille) flow and/or as Knudsen flow (Fig. 1). Which flow prevails depends on the ratio between the pore diameter $d$ and the mean free path of the gas molecule in the pores $\lambda$, called Knudsen number:

$K n=\frac{\lambda}{d}$

For $K n \gg 1$ (small pores), where the number of moleculewall collisions exceeds the one of intermolecular collisions, the permeation is better described by the Knudsen model. For $k n \ll 1$ (large pores), the permeation follows a viscous flow where intermolecular collisions dominate. For $k n \sim 1$, the so-called transition flow applies where a combination of both regimes occurs.

According to Kim et al. (2009), $\lambda$ can be approximated by:

$\lambda=\frac{\kappa \cdot T}{\sqrt{2} \pi \cdot p \cdot d_{\mathrm{m}}^{2}}$

where $\kappa$ is the Boltzmann constant, $p$ is the pressure, and $d_{\mathrm{m}}$ is the diameter of the gas molecule.

In the following the basic equations describing Knudsen flow and viscous flow are outlined, based on a review by Rutherford and Do (1997) and Choi et al. (2001). Here,

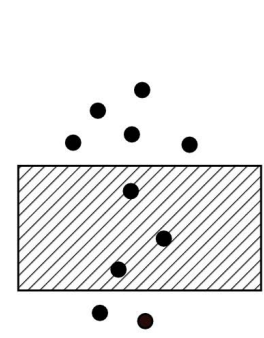

(a)

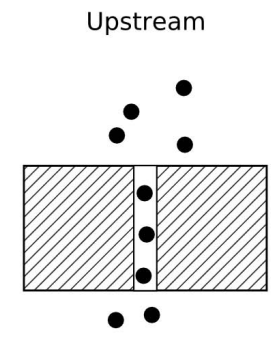

(b)

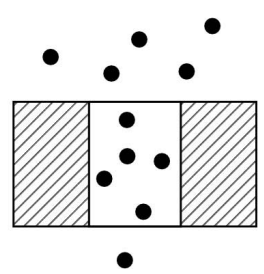

(c)
Fig. 1. Permeation mechanisms: (a) solution-diffusion based on Fick's law, (b) Knudsen flow prevailing at small pores, (c) viscous or Poiseuille flow occurring at large pores.

the temperature dependence of the permeation rate for both regimes is given and later (Sect. 5) compared with experimental results.

\subsubsection{Knudsen flow (small pores)}

Knudsen diffusion dominates the transport regime if the pore sizes are small $(k n \gg 1)$. In this case, the analyte flow depends on the concentration difference and hence on the partial vapour pressure difference. In practice, where the permeation device is flushed by an analyte-free carrier gas, the diffusion coefficient depends only on the vapour pressure $p_{v}$ of the analyte within the permeation device. The diffusion constant for Knudsen flow is parameterized as (Rutherford and Do, 1997):

$D_{K}=\frac{d}{3} \sqrt{\frac{8 \cdot R \cdot T}{\pi M}}$

where $M$ is the molecular weight. The steady state flow is described as (Choi et al., 2001):

$J_{K}=D_{K} \cdot \frac{\epsilon \cdot p_{v}}{\tau \cdot R \cdot T \cdot l}$

with $\epsilon$ the porosity, $p_{v}$ the analyte vapour pressure, and $\tau$ the tortuosity factor. The latter is in the most simple manner just the ratio between the real pathway a molecule travels through the polymer and the direct path, in our case the membrane thickness $l$ (Epstein, 1989).

Most parameters in Eqs. (9) and (10) are material constants, parameters, or physical constants and thus independent of temperature. Combing them to $J_{K}^{0}$, the permeation rate described by the Knudsen flow shows the following temperature function:

$J_{K}=J_{K}^{0} \cdot \frac{p_{v}(T)}{\sqrt{T}}$,

with

$J_{K}^{0}=\frac{d \cdot \epsilon}{3 \tau \cdot l} \sqrt{\frac{8}{\pi \cdot M \cdot R}}$. 


\subsubsection{Viscous flow (large pores)}

If the pore sizes are large compared to the mean free path $(k n \ll 1)$, the number of intermolecular collisions dominate and the flow is governed by viscous flow in the gaseous phase. Such transport, in contrast to Knudsen flow, is driven by the total pressure gradient. The diffusion coefficient is defined as (Rutherford and Do, 1997)

$D_{V}=\frac{d^{2} \cdot \bar{p}}{32 \mu}$

where $\mu$ is the gas viscosity and $\bar{p}$ the mean pressure within the permeating membrane, i.e. $\bar{p}=\left(p_{v}+p_{\text {air }}\right) / 2$, with $p_{\text {air }}$ the total pressure in the carrier gas. At steady state the flux is (Choi et al., 2001):

$J_{V}=\frac{D_{V} \cdot \epsilon}{\tau \cdot R \cdot T \cdot l} \Delta p$

where $\Delta p$ is the pressure difference below/above the membrane or inside/outside the permeation device, $\Delta p=p_{v}-$ $p_{\text {air. }}$.

The gas viscosity $\mu$ shows the following temperature dependence

$\mu=\mu_{0}\left(T_{0}\right) \cdot \frac{T_{0}+C_{\mathrm{S}}}{T+C_{\mathrm{S}}} \cdot\left(\frac{T}{T_{0}}\right)^{3 / 2}$

with $\mu_{0}\left(T_{0}\right)$ the gas viscosity at the reference temperature $T_{0}$ of typically $298.15 \mathrm{~K}$ and $C_{\mathrm{S}}$ the Sutherland's constant. As $C_{\mathrm{S}}$ of acetone is with $542 \mathrm{~K}$ very high (Hoffmann, 1962), $\mu$ roughly scales with $T^{3 / 2}$. Therefore, the temperature dependence of the viscous flow can be expressed as:

$J_{V}=J_{V}^{0} \cdot \frac{\left(p_{v}(T)+p_{\text {air }}\right) \cdot\left(p_{v}(T)-p_{\text {air }}\right)}{\left(T / T_{0}\right)^{5 / 2}}$

with

$J_{V}^{0}=\frac{d^{2} \cdot \epsilon}{16 \mu_{0}\left(T_{0}\right) \cdot \tau \cdot R \cdot l}$

\subsection{The stabilization time}

As outlined in the introduction, one drawback of permeation sources is the long stabilization time, i.e. the time lag between the stabilization of temperature and permeation rate. According to Rutherford and Do (1997), this stabilization time for the Knudsen and viscous regime, $\theta_{K}$ and $\theta_{V}$, is:

$\theta_{K}=\frac{l^{2}}{6 D_{K}} \quad$ (Knudsen flow)

and

$\theta_{V}=\frac{l^{2}}{3 D_{V}} \quad$ (viscous flow)

That is, in both cases the stabilization time scales with the square of the membrane thickness $l$. This strong dependence forced us to choose a thin membrane for our permeation device which is still robust enough to withstand the pressure gradient $\Delta p$. The expected short stabilization times are confirmed in Sect. 5 where the measured time lag is compared with the Eqs. (18) and (19).

\subsection{Conclusion on theoretical analysis}

In Sect. 3.1 the two possible approaches describing the permeation of gases through polymers are outlined. Two important characteristics are common to them: (1) a strong relationship between permeation rate and temperature. (2) The strong (mostly exponential) temperature dependence of the analyte vapour pressure dominates the temperature dependence of the permeation rate. The question finally is what flow regime holds for PTFE, the most widely used polymer for permeation devices. In PTFE a broad range of pore sizes have been measured, primarily between 0.3 and $0.7 \mu \mathrm{m}$ (Xiuli et al., 2003). The mean free path for acetone at room temperature (where its vapour pressure is $\sim 500 \mathrm{hPa}$ ) is $\sim 0.05 \mu \mathrm{m}$ (Eq. 8). Hence, with $k n \sim 10$ the viscous flow regime is expected to dominate. In Sect. 5, we will assess what flow regime describes our experimental results best. Further note that hysteresis effects can occur in systems where absorbed molecules are strongly bound in the polymer, a process that is not expected in PTFE (Duncan et al., 2005).

\section{Experimental}

\subsection{The PTRMS technique}

The characterization of the presented calibration source was performed using the experimental setup shown in Fig. 2. The acetone measurements were done with a PTR mass spectrometer, as described in detail by (Lindinger et al., 1998; de Gouw and Warneke, 2007; Blake et al., 2009).

The calibration source (described in the next section) was filled with isotopically labelled acetone, namely D-6 acetone (Aldrich Chemical Co., USA) having a mass of $64 \mathrm{amu}$, in contrast to natural (atmospheric) acetone with mass of $58 \mathrm{amu}$. This isotope labelling of calibration gas is an often applied technique in mass spectrometry. In this case the calibration gas can permanently be added to the sample flow. Besides negligible isotope fractionation effects, it behaves chemically identical as the gas in the sample gas, but is detected at another mass with losing very little sampling time (Bandy et al., 1993; Blomquist et al., 2010; Roiger et al., 2011). Moreover, it allows higher measurement accuracy due to the (almost) continuous calibration, in contrast to occasional calibrations with calibration gas cylinders. This advantage is of particular importance during aircraft deployment where the air mass composition and thus parameters affecting the instrument sensitivity (e.g. humidity) may change quickly. Synthetic air was enriched with D6-acetone from the calibration gas system and measured. For verifying the 


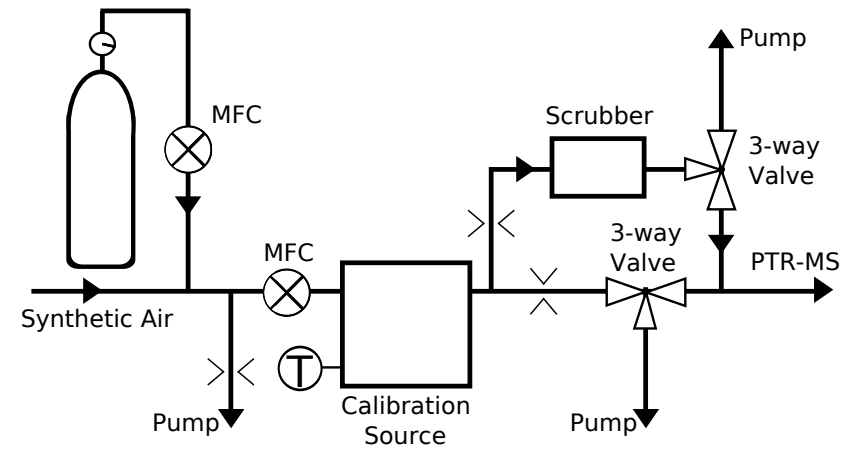

Fig. 2. Experimental setup. Sample air having a well-defined mixing ratio of acetone is generated (left side). For that, air from a cylinder filled with standard gas (Apel-Reimer Environmental, USA) having an acetone mixing ratio of $500 \mathrm{ppbv}$ is mixed with synthetic air. Two mass flow controllers (MFC) lead to a sample gas flow of $35 \mathrm{sccm}$ with an acetone mixing ratio of $16.1 \mathrm{ppbv}$. This air flow is guided through the calibration gas source filled with isotopically labelled acetone, latter referred as D6-acetone. Thereafter, the air goes either directly into a PTR mass spectrometeror before through a VOC scrubber (Pt-catalyst controlled to $350^{\circ} \mathrm{C}$ ) for measuring the background signal.

stability of the calibration system, once every 100 min natural acetone from the calibration gas cylinder was added for $10 \mathrm{~min}$ and for another $10 \mathrm{~min}$ the background signal was measured using VOC-free air generated by guiding the sample air through the VOC scrubber (zero air).

\subsection{The unheated permeation device}

As outlined in the introduction, permeation sources are usually controlled to a defined temperature. The device described here is unheated, i.e. its permeation rate floats in dependence of the temperature gradient between outside and inside of the device, its heat capacity, and its thermal insulation to the environment. The only way to accurately derive the permeation rate is to guarantee that the parameters determining the instantaneous permeation rate follow the temperature drift of the system $\mathrm{d} T / \mathrm{d} t$. In this case, the permeation is in thermal equilibrium and the permeation rate is only a function of the temperature of the device which can simply and accurately be measured. This equilibrium condition is achieved by considering two technical features for our permeation system: (i) by using a thin membrane (having a surface of only some $\mathrm{mm}^{2}$ ) instead of the usually applied much bigger permeation tubes with larger wall thickness. Such a membrane strongly reduces the stabilization time $\theta$ (Eqs. 18 and 19). (ii) By strongly reducing the temperature drift of the system by a combination of an extremely efficient insulation and a large heat capacity of the system. A schematic view of the permeation system is indicated in Fig. 3.

It consists of a stainless-steel (SS) cube filled with $\sim 0.71$ of water which has (besides ammonia) the largest specific

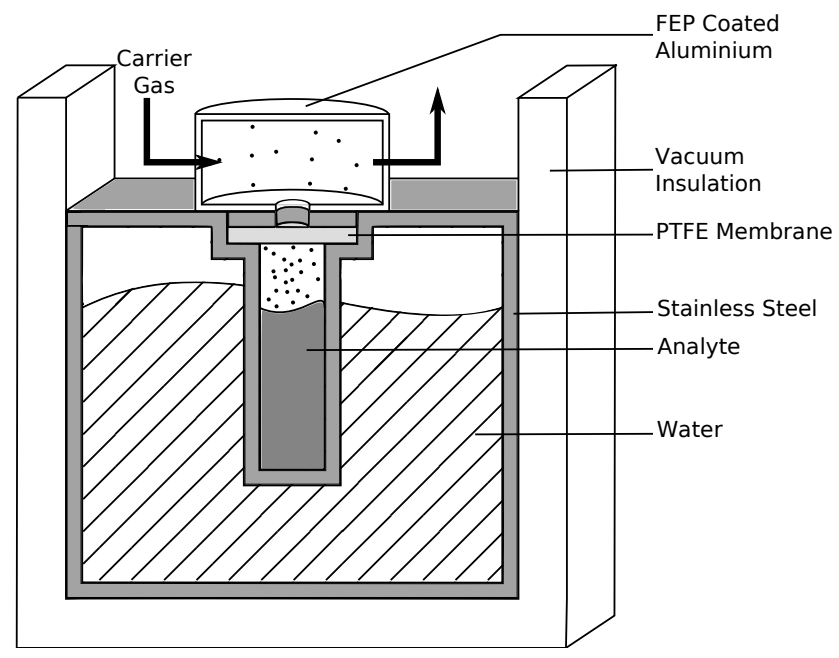

Fig. 3. Schematic view of the calibration system. Five $0.35 \mathrm{ml}$ cylindrical recipients (here, only one is shown) filled with different liquid analytes are surrounded by a water bath. The $0.4 \mathrm{~mm}$ thick PTFE membrane works as permeating polymer and provides sealing for the liquid analyte. The "active" area through which permeation occurs is $6 \mathrm{~mm}^{2}$. A fluorinated ethylene propylene (FEP) coated aluminium cap sealed with viton O-rings encloses the five permeation membranes. Sample gas enters and leaves the system via perfluoroalkoxy (PFA) fittings fixed into the cap.

heat capacity $\mathrm{c}_{\mathrm{v}}(4.2 \mathrm{~kJ}(\mathrm{~kg} \mathrm{~K}))$ of any substance. Five recipients each having a volume of $0.35 \mathrm{ml}$ for up to five different analytes are immersed into the water bath and thus have exactly the same temperature as the SS cube and the water bath. Its temperature is accurately measured using three NTC thermistors glued on different places of the SS cube for higher accuracy. The PTFE membrane is pressed into the SS cube by a $1 \mathrm{~mm}$ thick SS disc. The membrane is $0.4 \mathrm{~mm}$ thick and has a diameter of $\sim 2.8 \mathrm{~mm}$ which results in an active surface of only $\sim 6 \mathrm{~mm}^{2}$ compared to $\sim 400 \mathrm{~mm}^{2}$ of typical commercially available permeation tubes (having a length of $\sim 20 \mathrm{~mm}$ and a diameter of $\sim 1 / 4$ ). The entire system is enclosed with six $4 \mathrm{~cm}$ thick vacuum insulation bricks (va-Qtec, Germany) that have an extremely low thermal conductivity of less than $0.005 \mathrm{~W} /(\mathrm{m} \mathrm{K})$, comparable to an insulation of 30-40 cm with typical insulation foam. To prevent saturation of the sealing materials and the inlet/outlet lines of the calibration device during power down, a sophisticated venting system was developed. It consists of a micro diaphragm pump (Gardner Denver Thomas, USA) that consumes only $35 \mathrm{~mW}$ and enables a flow of $150 \mathrm{sccm}$ (standard cubic centimetre per minute). It is powered by two goldcap capacitors, each with a capacity of 1500 Farad at $2.5 \mathrm{~V}$ (BOOSTCAP, Maxwell Technologies, USA). A tiny electronic circuit switches the micro pump on and off for $20 \mathrm{~s}$ each. The energy stored in the goldcaps is sufficient to power the pump for about ten days and thus easily bridges possible transportation time to and from the airport or times in the laboratory when 
the system is switched off. The entire calibration system along with the venting system weighs altogether less than $3 \mathrm{~kg}$.

\subsection{Temperature drift of the permeation rate}

In this section, we calculate the temperature drift of the device $\mathrm{d} T / \mathrm{d} t$ in dependence of the temperature gradient between outside and inside the calibration system and finally compare the result with the measured temperature drift. The permeation device has two main pathways leading to a heating power $(H)$ : (i) across the insulation $H_{\text {ins }}$ and (ii) the inflowing sample air $H_{\text {air }}$.

$H=H_{\text {ins }}+H_{\text {air }}$

$H_{\text {ins }}$ is the product of the heat conductance of the vacuum insulation box given by the manufacturer of $U_{\text {ins }}=0.017 \mathrm{~W} / \mathrm{K}$ and the temperature gradient across the insulation $\Delta T . H_{\text {air }}$ is the product of the heat capacity of the inflowing sample air $\mathrm{c}_{\mathrm{v} \text {,air }}(=28.97 \mathrm{~J} /(\mathrm{mol} \mathrm{K}))$, its flow through the device $j_{\text {air }}$ $(=35 \mathrm{sccm})$ and the temperature gradient between the inflowing sample air and the inner temperature, assumed to be $\Delta T$ as well:

$H=U_{\text {ins }} \cdot \Delta T+c_{v, \text { air }} \cdot j_{\text {air }} \cdot \Delta T$

This heating power $H$ results in a temperature drift of the device $\mathrm{d} T / \mathrm{d} t$ which is solely determined by the heat capacity of the device:

$$
\begin{aligned}
H & =\mathrm{d} Q / \mathrm{d} T \\
& =C_{\mathrm{v}} \cdot \mathrm{d} T / \mathrm{d} t
\end{aligned}
$$

The heat capacity of the device $C_{\mathrm{v}}$ is the sum of the heat capacity of the water and the stainless steel (SS):

$$
\begin{aligned}
C_{\mathrm{v}} & =m_{\text {water }} \cdot c_{\mathrm{v}, \text { water }}+m_{\mathrm{SS}} \cdot c_{\mathrm{v}}, \mathrm{SS} \\
& =0.7 \mathrm{~kg} \cdot 4.2 \mathrm{~kJ} /(\mathrm{kgK})+0.6 \mathrm{~kg} \cdot 0.5 \mathrm{~kJ} /(\mathrm{kgK}) \\
& =3.24 \mathrm{kJK}^{-1}
\end{aligned}
$$

Combing Eqs. (21)-(23), resolving it to $\mathrm{d} T / \mathrm{d} t$, and inserting all physical constants leads to:

$$
\begin{aligned}
\mathrm{d} T / \mathrm{d} t & =\left(U_{\text {ins }}+C_{\mathrm{v}, \text { air }} \cdot j_{\text {air }}\right) \cdot \Delta T / C_{\mathrm{v}} \\
& =\left(17 \mathrm{mWK}^{-1}+0.7 \mathrm{mWK}^{-1}\right) \cdot \Delta T / C_{\mathrm{v}} \\
& =20 \mathrm{mKh}^{-1} \cdot \Delta T \quad(\Delta T \text { in } \mathrm{K})
\end{aligned}
$$

We also measured the temperature drift of the device by cooling it (without insulation) in a refrigerator to $\sim 1^{\circ} \mathrm{C}$, encased it thereafter by the insulation elements, and measured its temperature drift together with the temperature of the ambience (of $\sim 25^{\circ} \mathrm{C}$ ) during $\sim 20 \mathrm{~h}$. The measured temperature drift amounted to $30( \pm 1) \mathrm{mK} \mathrm{h}^{-1}$ per Kelvin temperature gradient over the entire period of $20 \mathrm{~h}$, i.e. exactly a factor of 1.5 larger than the calculated one (Eq. 24). This (tolerable) difference may largely be explained by a $\sim 0.5 \mathrm{~cm}^{2}$ large hole in the vacuum insulation box acting as feedthrough for the inlet and outlet sample line and the cables for the temperature measurements and by the fact that the altogether six insulation elements are not agglutinated in order to allow facile access. Both, the hole and the avoidance of the agglutination were not considered in the heat conductance of the vacuum insulation box given by the manufacturer.

\section{Results}

In this section, the properties of the new calibration device are addressed.

\subsection{Determination of stabilization time}

In order to measure the stabilization time $\theta$ of the calibration source, the insulation around the calibration device was removed and the temperature controlled to $43^{\circ} \mathrm{C}$ (by using a heating wire wrapped around the device) for some hours to guarantee complete thermal equilibrium and a constant permeation rate. Thereafter, the temperature control was switched off so that the system cooled with a rate of about $-7 \mathrm{~K} \mathrm{~h}^{-1}$. After two hours the heating was switched on again in order to control the temperature to then $30^{\circ} \mathrm{C}$. Figure 4 depicts the temperature of the permeation device and the measured D6-acetone mixing ratio. During the entire test period of $18 \mathrm{~h}$ the permeation device was flushed with synthetic air and the mixing ratio of D6-acetone permeated into the synthetic air was measured by the PTRMS (Fig. 2).

Figure 4 shows the almost simultaneous decrease of temperature and permeation rate. After temperature stabilization (at $\sim 120 \mathrm{~min}$ ), it took only another $\sim 18$ min until the permeation rate stabilized. Such short stabilization time can be compared with equations inferred for Knudsen flow (Eq. 18) and viscous flow (Eq. 19), using the parameters listed in Table 1 .

Table 1. Parameters used for calculating the stabilization times for Knudsen flow and viscous flow.

\begin{tabular}{lrl}
\hline Parameter & Value & Unit \\
\hline Membrane thickness $(l)$ & 0.4 & $\mathrm{~mm}$ \\
Mean temperature $(T)$ & 309 & $\mathrm{~K}$ \\
Diameter acetone molecule $\left(d_{\mathrm{m}}\right)$ & 0.63 & $\mathrm{~nm}$ \\
molecular weight of D6-acetone $(M)$ & 64.1 & $\mathrm{~g} \mathrm{~mol}^{-1}$ \\
Gas viscosity $(\mu)$ & 7.9 & $\mu \mathrm{Pa} \mathrm{s}^{-1}$ \\
Vapour pressure of acetone $\left(p_{v}\right)$ & 467.7 & $\mathrm{hPa}$ \\
Air pressure $\left(p_{\text {air }}\right)$ & 40 & $\mathrm{hPa}$ \\
\hline
\end{tabular}

With these parameters, stabilization times for Knudsen flow of $\theta_{K}=13 \mathrm{~s}$ and for viscous flow of $\theta_{V}=21.6 \mathrm{~min}$ are calculated. The surprisingly good agreement with the observed stabilization time of $\sim 18 \mathrm{~min}$ (Fig. 4 ) indicates that the permeation is indeed better described by the viscous 

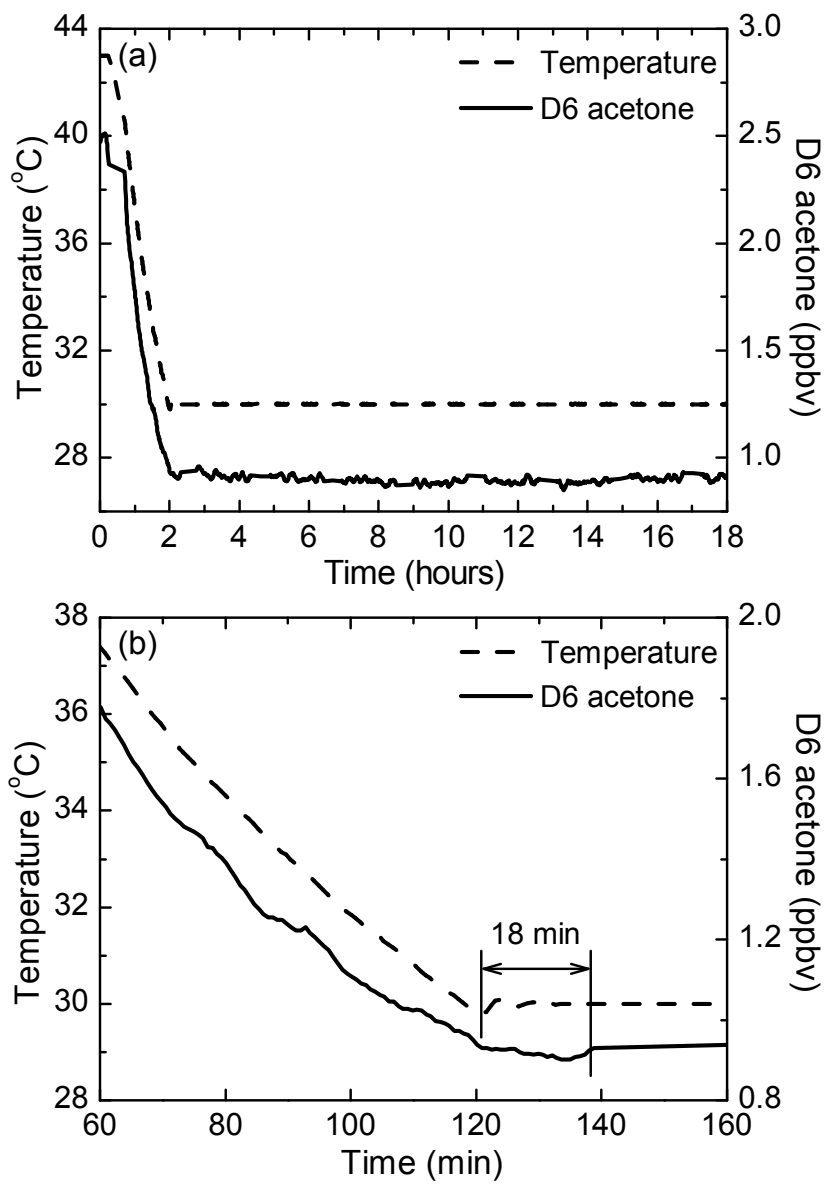

Fig. 4. Temperature of the permeation device (dashed line) and D6-acetone mixing ratio (straight line) during the entire test period of $18 \mathrm{~h}$ (graph a) and during $100 \mathrm{~min}$ around the stabilization point (graph b).

model, as already speculated in Sect. 3.3. This in turn implicates that the majority of the pores in the used PTFE membrane are large compared to the mean free path length of the acetone molecules in the membrane.

\subsection{Temperature dependence of permeation rate}

Using the experimental setup shown in Fig. 2, the permeation rate was repeatedly measured at various temperatures between 21 and $45^{\circ} \mathrm{C}$ (Fig. 5).

The error bars indicate the variability of the typically six measurement sequences at a certain temperature. At the lowest temperature $\left(21^{\circ} \mathrm{C}\right)$ only one measurement was performed, because otherwise the laboratory temperature was higher. As discussed in Sect. 2 (Eq. 1), the observed temperature dependence of the permeation rate (Fig. 5) indeed fits extremely well an Arrhenius-like behaviour:

$P=3.34 \cdot 10^{10} \cdot \exp \left(\frac{-6023.66}{T}\right)$

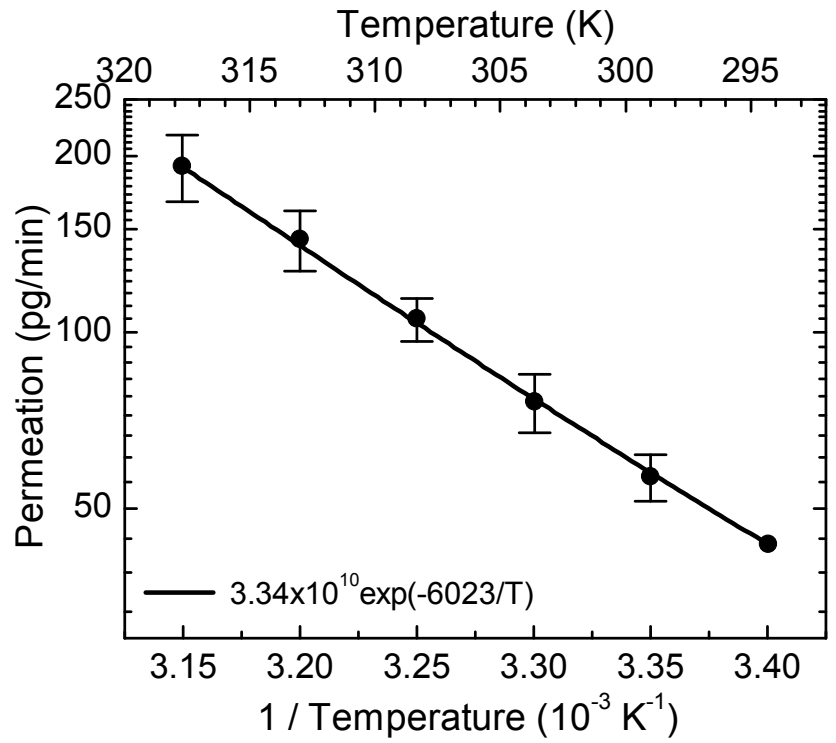

Fig. 5. Permeation rate as function of temperature. Dots: average permeation rate obtained in six temperature cycles and two hours measurement at each temperature step. The standard deviation is indicated by the error bars. At $21^{\circ} \mathrm{C}$, only one complete run was achievable. Line: fit to an Arrhenius equation with a correlation coefficient $R^{2}$ of 0.999 .

with $T$ in Kelvin and $P$ in $p g \min ^{-1}$. The derivative of equation 25 gives the change of permeation rate with temperature, being $\sim 6.6 \%$ per Kelvin at $\sim 30^{\circ} \mathrm{C}$. This strong temperature dependence is dominated by the temperature dependent vapour pressure $p_{v}$, see Eqs. (11) and (16). Ambrose et al. (1974) gives a vapour pressure of acetone of

$p_{v}=1.75 \cdot 10^{9} \cdot \exp \left(\frac{-3517.5}{\mathrm{~T}-49}\right)$.

with $T$ in Kelvin and $p_{v}$ in hPa. The derivative of Eq. (26) shows an increase of $\sim 4.0 \%$ per Kelvin around $30^{\circ} \mathrm{C}$. The remaining change in permeation rate of $\sim 2.6 \%$ per Kelvin can be attributed to the temperature dependence of the diffusion coefficients (Eqs. 11 and 16).

\subsection{Flow regime in current permeation device}

The next logical step is to fit the equations inferred for Knudsen flow (Eq. 11) and viscous flow (Eq. 16) to the measured temperature dependence of the permeation rate, in order to further specify the nature of the dominating permeation process. As two material parameters of the used PTFE membrane, namely the porosity $\epsilon$ and the tortuosity factor $\tau$, are not known, the two constants $J_{K}^{0}$ and $J_{V}^{0}$ were simply chosen to best fit the measured permeation rate.

As seen in Fig. 6, the measured temperature dependence or slope, respectively, lies between the two theoretical approaches, however, much closer at the viscous flow regime. Remember that also the measured stabilization time of the 


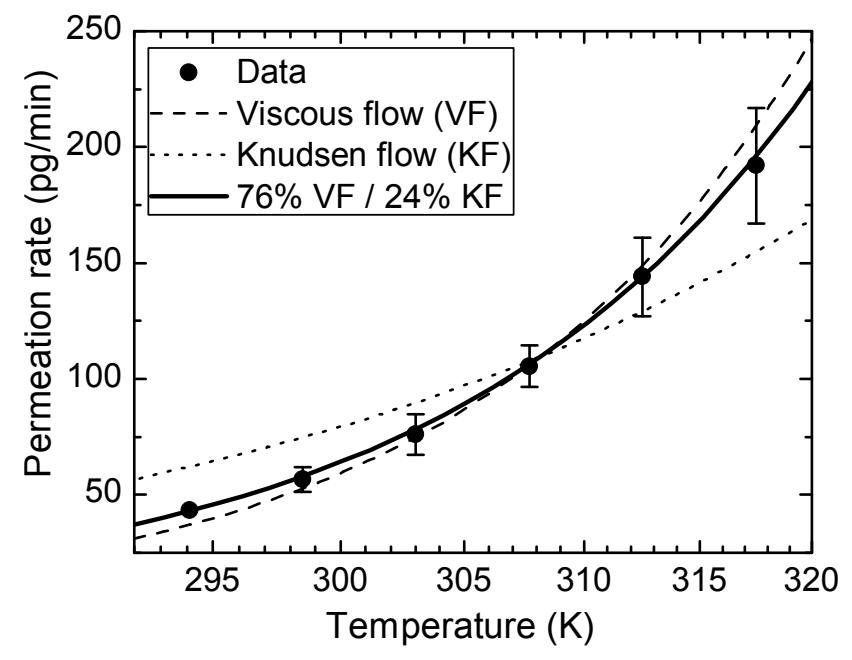

Fig. 6. Permeation rate as function of temperature. Dots: measured data with $1-\sigma$ variability (error bars). Fit lines for Knudsen flow (dotted, equation 11) and viscoud flow (dashed, Eq. (16)). Full line: combination of both flow regimes, see text.

permeation device was between the two calculated values and much better approximated by the viscous flow regime (Sect. 5.1).

As the membrane will also contain small pores and as the observed temperature dependence is between the two theoretical approaches, we furthermore tested if the measured permeation rate can as first guess be approximated as linear combination of the two model approaches, i.e.

$P(T)=x \cdot P_{\text {viscous }}(T)+(1-x) \cdot P_{\text {Knudsen }}(T)$

A least squares fit indicated a contribution $x$ of $76 \%$ by viscous flow and $24 \%$ by Knudsen flow. Indeed, this simple linear combination works excellently (full line in Fig. 6).

In conclusion, two observables, i.e. the stabilization time and the temperature dependence of the permeation rate, are well described with the theoretical description of permeation of gases through porous polymers, and furthermore, agrees with the knowledge of pore sizes in PTFE, see Sect. 3.3.

\section{Temperature-driven drift of permeation rate}

With the information provided in the last sections, the drift of the permeation rate due to changing temperatures and the associated error in the assumed permeation rate can be inferred. As indicated in Sect. 4.3 the measured temperature drift due to heat transfer across the insulation is $\mathrm{d} T / \mathrm{d} t=30 \mathrm{mK} \mathrm{h}^{-1}$. $\Delta T$. Assuming an large temperature gradient between outside and inside the permeation rate of $\Delta T=20 \mathrm{~K}$, the temperature drift is $\mathrm{d} T / \mathrm{d} t=600 \mathrm{mK} \mathrm{h}^{-1}$. During the observed stabilization time of $18 \mathrm{~min}$, the temperature has thus drifted by $180 \mathrm{mK}$. With the temperature dependence of the permeation rate of $\sim 6.6 \%$ per Kelvin (Sect. 5.2), this small temperature drift only results in a drift of the permeation rate by $1.2 \%$.

Such a smal drift is negligible compared to the sum of all other uncertainties associated with the calibration of instruments for VOC measurements of at least $10 \%$. Moreover, as the course of the temperature of the permeation device is precisely measured, this drift can even be considered in the determination of the instantaneous permeation rate.

\section{Possible applications}

The properties of this new type of calibration device for insitu VOC measurements can clearly be defined. The advantages are low weight, small size, simplicity and robustness, and missing demand of electrical power. It is further little susceptible to contamination and wall losses, as they may occur for many species in calibration gas cylinders (see Sect. 1). However and as in the case of all permeation devices, it can be filled only with compounds having vapour pressures of below 1 bar at ambient temperatures, i.e. which are liquid. That is, the calibration device cannot be used for alkanes and low number $(\leq \mathrm{C} 4)$ alkenes.

A further, in our opinion the most critical disadvantage is that the recipients cannot be weighed, i.e. the permeation rate has to be measured before use over the entire range of possible temperatures (usually 15 to $35^{\circ} \mathrm{C}$ ) with an independent calibration device and should be cross-checked in time steps of some months to confirm the initially measured permeation rate. One can thus view this calibration device as a working standard that has to be checked once in a while by a laboratory standard. In particular the latter property let us assume that the use of this permeation device will be limited to field applications, such as on board aircraft, where the striking advantages outrival this disadvantage.

\section{Conclusions}

A robust, unpowered permeation device for calibrating insitu instruments for VOC measurements during field use is presented. The system is modestly small $(15 \times 15 \times 15 \mathrm{~cm})$ and lightweight ( $3 \mathrm{~kg}$, with venting system). It overcomes the dominating shortcoming of usual permeation devices, that is the need of permanent temperature stabilization. Without temperature control the uncertainty of the permeation rate due to thermal non-equilibrium is below $1 \%$ (shown for acetone), even at temperature gradients of $30 \mathrm{~K}$.

The physical fundamentals for the permeation of gases (here, acetone) through polymers (here, PTFE) are addressed in an extensive theory part. The three major transport processes of gases through porous polymers are described and all equations required to characterize the permeation process are given. This theoretical framework is easily applicable to other gases and polymers and thus helps to design the optimum technical realization for the respective application. By 
modifying the surface of the permeating polymer (the membrane) and the flow of zero air through the device, arbitrary gas mixing ratios between $<100 \mathrm{pptv}$ and $>100 \mathrm{ppbv}$ can be generated.

Since May 2010 the system is successfully used once a month during four long-distance flights onboard the CARIBIC passenger aircraft (Brennikmeijer et al., 2005; Sprung and Zahn, 2010) for calibrating acetone measurements. The extension to further species will be implemented soon.

Acknowledgements. We acknowledge the support of the Deutsche Forschungsgemeinschaft and of the European Commission through the GEOmon (Global Earth Observation and Monitoring) Integrated Project under the 6th Framework Program (contract FP6-2005-Global-4-036677).

Edited by: D. Riemer

\section{References}

Apel, E., Calvert, J., and Fehsenfeld, F.: The nonmethane hydrocarbon intercomparison experiment (NOMHICE): Tasks 1 and 2, J. Geophys. Res., 99, 16651, 1994.

Apel, E., Calvert, J., Greenberg, J., Riemer, D., Zika, R., Kleindienst, T., Lonneman, W., Fung, K., and Fujita, E.: Generation and validation of oxygenated volatile organic carbon standards for the 1995 Southern Oxidants Study Nashville Intensive, J. Geophys. Res., 103, 22281-22294, 1998.

Atkinson, R.: Atmospheric chemistry of VOCs and NOx, Atmos. Environ., 34, 2063-2101, 2000.

Bandy, A., Thornton, D., and Driedger III, A.: Airborne Measurements of Sulfur Dioxide, Dimethyl Sulfide, Carbon Disulfide, and Carbonyl Sulfide by Isotope Dilution Gas Chromatography, J. Geophys. Res., 98, 23423-23433, 1993.

Barratt, R.: The preparation of standard gas mixtures. A review, The analyst, 106, 817-849, 1981.

Blake, R., Monks, P., and Ellis, A.: Proton-Transfer Reaction Mass Spectrometry, Chem. Rev., 109, 711-724, 2009.

Blomquist, B. W., Huebert, B. J., Fairall, C. W., and Faloona, I. C.: Determining the sea-air flux of dimethylsulfide by eddy correlation using mass spectrometry, Atmos. Meas. Tech., 3, 1-20, doi:10.5194/amt-3-1-2010, 2010.

Brennikmeijer, C., Slemr, F., Koeppel, C., Scharffe, D., Pupek, M., Lelieveld, J., Crutzen, P., Zahn, A., Sprung, D., Fischer, H., Hermann, H., Heintzenberg, J., Schlager, H., Ziereis, H., Schumann, U., Dix, B., Platt, U., Ebinghaus, R., Martinsson, B., Ciais, P., Filippi, D., Leuenberger, M., Oram, D., Penkett, S., van Velthoven, P., and Waibel, A.: Analyzing Atmospheric Trace Gases and Aerosols Using Passenger Aircraft, EOS, 86, 77-88, 2005.

Choi, J., Do, D., and Do, H.: Surface diffusion of adsorbed molecules in porous media: Monolayer, multilayer, and capillary condensation regimes, Ind. Eng. Chem. Res., 40, 4005-4031, 2001.

de Gouw, J. and Warneke, C.: Measerurements of Volatile Organic Compounds In the Earth's Atmosphere Using Proton-Transfer-
Reaction Mass Spectrometry, Mass Spec. Rev., 26, 223-257, 2007.

de Gouw, J. A., Middlebrook, A. M., Warneke, C., Ahmadov, R., Atlas, E. L., Bahreini, R., Blake, D. R., Brock, C. A., Brioude, J., Fahey, D. W., Fehsenfeld, F. C., Holloway, J. S., Le Henaff, M., Lueb, R. A., McKeen, S. A., Meagher, J. F., Murphy, D. M., Paris, C., Parrish, D. D., Perring, A. E., Pollack, I. B., Ravishankara, A. R., Robinson, A. L., Ryerson, T. B., Schwarz, J. P., Spackman, J. R., Srinivasan, A., and Watts, L. A.: Organic Aerosol Formation Downwind from the Deepwater Horizon Oil Spill, Science, 331, 1295-1299, 2011.

Duncan, B., Urquhart, J., and Roberts, S.: Review of Measurement and Modelling of Permeation and Diffusion in Polymers, NPL Report DEPC MPR 012, 12, 1-73, 2005.

Epstein, N.: On tortuosity and the tortuosity factor in flow and diffusion through porous media, Chem. Eng. Sci., 44, 777-779, 1989.

Gautrois, M. and Koppmann, R.: Diffusion technique for the production of gas standards for atmospheric measurements, J. Chromatogr. A, 848, 239-249, 1999.

Hoffmann, E.: Calculation of Relative Molar Response Factors of Thermal Conductivity Detectors in Gas Chromatography, Anal. Chem., 34, 1216-1222, 1962.

Isaacman, G., Kreisberg, N. M., Worton, D. R., Hering, S. V., and Goldstein, A. H.: A versatile and reproducible automatic injection system for liquid standard introduction: application to insitu calibration, Atmos. Meas. Tech., 4, 1937-1942, 2011, http://www.atmos-meas-tech.net/4/1937/2011/.

Jardine, K. J., Henderson, W. M., Huxman, T. E., and Abrell, L.: Dynamic Solution Injection: a new method for preparing pptvppbv standard atmospheres of volatile organic compounds, Atmos. Meas. Tech., 3, 1569-1576, doi:10.5194/amt-3-15692010, 2010.

Jenkin, M., Saunders, S., and Pilling, M.: The tropospheric degradation of volatile organic compounds: a protocol for mechanism development, Atmos. Environ., 31, 81-104, 1997.

Jimenez, J. L., Canagaratna, M. R., Donahue, N. M., Prevot, A. S. H., Zhang, Q., Kroll, J. H., DeCarlo, P. F., Allan, J. D., Coe, H., Ng, N. L., Aiken, A. C., Docherty, K. S., Ulbrich, I. M., Grieshop, A. P., Robinson, A. L., Duplissy, J., Smith, J. D., Wilson, K. R., Lanz, V. A., Hueglin, C., Sun, Y. L., Tian, J., Laaksonen, A., Raatikainen, T., Rautiainen, J., Vaattovaara, P., Ehn, M., Kulmala, M., Tomlinson, J. M., Collins, D. R., Cubison, M. J., E., Dunlea, J., Huffman, J. A., Onasch, T. B., Alfarra, M. R., Williams, P. I., Bower, K., Kondo, Y., Schneider, J., Drewnick, F., Borrmann, S., Weimer, S., Demerjian, K., Salcedo, D., Cottrell, L., Griffin, R., Takami, A., Miyoshi, T., Hatakeyama, S., Shimono, A., Sun, J. Y., Zhang, Y. M., Dzepina, K., Kimmel, J. R., Sueper, D., Jayne, J. T., Herndon, S. C., Trimborn, A. M., Williams, L. R., Wood, E. C., Middlebrook, A. M., Kolb, C. E., Baltensperger, U., and Worsnop, D. R.: Evolution of Organic Aerosols in the Atmosphere, Science, 326, 1525-1529, 2009.

Jost, C.: Calibration with permeation devices: is there a pressure dependence of the permeation rates?, Atmos. Environ., 38, 35353538, 2004.

Kim, H., Han, Y., and Park, J.: Evaluation of permeable pore sizes of macroporous materials using a modified gas permeation method, Mater. Charact., 60, 14-20, 2009.

Klopffer, M. and Flaconneche, B.: Transport properties of gases in polymers: bibliographic review, Oil Gas Sci. Technol., 56, 223 
$244,2001$.

Lindinger, W., Hansel, A., and Jordan, A.: On-line monitoring of volatile organic compounds at pptv levels by means of protontransfer-reaction mass spectrometry (PTR-MS) medical applications, food control and environmental research, Int. J. Mass Spectrom., 173, 191-241, 1998.

Michaels, A. and Bixler, H.: Flow of gases through polyethylene, J. Polym. Sci., 50, 413-439, 1961a.

Michaels, A. and Bixler, H.: Solubility of gases in polyethylene, J. Polym. Sci., 50, 393-412, 1961 b.

Mitchell, G.: A review of permeation tubes and permeators, Separ. Purif. Rev., 29, 119-128, 2000.

Mohamed, H., Abdel-Hady, E. E., and Mohamed, S.: Temperature dependence of the free volume in polytetrafluoroethylenestudied by positron annihilation spectroscopy, Radiat. Phys. Chem., 76, 160-164, proceedings of the 8th International Workshop on Positron and Positronium Chemistry, 2007.

Namiesnik, J.: Generation of standard gaseous mixtures, J. Chromatogr. A, 300, 79-108, 1984.

Odum, J., Hoffmann, T., Bowman, F., Collins, D., Flagan, R., and Seinfeld, J.: Gas/particle partitioning and secondary organic aerosol yields, Environ. Sci. Technol., 30, 2580-2585, 1996.

Odum, J., Jungkamp, T., Griffin, R., Forstner, H., Flagan, R., and Seinfeld, J.: Aromatics, reformulated gasoline, and atmospheric organic aerosol formation, Environ. Sci. Technol., 31, 18901897, 1997.

O'Keeffe, A. and Ortman, G.: Primary Standards for Trace Gas Analysis., Anal. Chem., 38, 760-763, 1966.

Pandey, P. and Chauhan, R.: Membranes for gas separation, Prog. Polym. Sci., 26, 853-893, 2001.

Pozzer, A., Pollmann, J., Taraborrelli, D., Jöckel, P., Helmig, D., Tans, P., Hueber, J., and Lelieveld, J.: Observed and simulated global distribution and budget of atmospheric $\mathrm{C}_{2}-\mathrm{C}_{5}$ alkanes, Atmos. Chem. Phys., 10, 4403-4422, doi:10.5194/acp-10-44032010, 2010.

Rappenglück, B., Apel, E., Bauerfeind, M., Bottenheim, J., Brickell, P., Čavolka, P., Cech, J., Gatti, L., Hakola, H., Honzak, J., Junek, R., Martin, D., Noone, C., Plass-Dülmer, C., Travers, D., and Wang, D.: The first VOC intercomparison exercise within the Global Atmosphere Watch (GAW), Atmos. Environ., 40, 7508-7527, 2006.

Rhoderick, G. C. and Miller, W. R.: Development of hydrocarbon gas standards, J. Chromatogr. A, 653, 71-81, 1993.

Roiger, A., Aufmhoff, H., Stock, P., Arnold, F., and Schlager, H.: An aircraft-borne chemical ionization - ion trap mass spectrometer (CI-ITMS) for fast PAN and PPN measurements, Atmos. Meas. Tech., 4, 173-188, doi:10.5194/amt-4-173-2011, 2011.

Rutherford, S. and Do, D.: Review of time lag permeation technique as a method for characterisation of porous media and membranes, Adsorption, 3, 283-312, 1997.

Singh, H., Kanakidou, M., Crutzen, P., and Jacob, D.: High concentrations and photochemical fate of oxygenated hydrocarbons in the global troposphere, Nature, 378, 50-54, 1995.
Sprung, D. and Zahn, A.: Acetone in the upper troposphere/lowermost stratosphere measured by the CARIBIC passenger aircraft: Distribution, seasonal cycle, and variability, J. Geophys. Res., 115, D16301, doi:10.1029/2009JD012099, 2010.

Stannett, V.: The transport of gases in synthetic polymeric membranes-an historic perspective, J. Membrane Sci, 3, 97-115, 1978.

Stern, S. A. and Trohalaki, S.: Fundamentals of Gas Diffusion in Rubbery and Glassy Polymers, ACS Publications, 3, 22-59, 1990.

Thompson, J. and Perry, D.: A new system of refillable and uniquely identifiable diffusion tubes for dynamically generating VOC and SVOC standard atmospheres at ppm andppb concentrations for calibration of field and laboratory measurements, J. Environ. Monitor., 11, 1543-1544, 2009.

Tumbiolo, S., Vincent, L., Gal, J., and Maria, P.: Thermogravimetric calibration of permeation tubes used for the preparation of gas standards for air pollution analysis, The Analyst, 130, 1369$1374,2005$.

Veres, P., Gilman, J. B., Roberts, J. M., Kuster, W. C., Warneke, C., Burling, I. R., and de Gouw, J.: Development and validation of a portable gas phase standard generation and calibration system for volatile organic compounds, Atmos. Meas. Tech. Discuss., 3, 333-357, doi:10.5194/amtd-3-333-2010, 2010.

VICI Metronics: Generating Calibration Gas Standards, Tech. rep., 2004.

Washenfelder, R., Roehl, C., McKinney, K., Julian, R., and Wennberg, P.: A compact, lightweight gas standards generator for permeation tubes, Rev. Sci. Instrum., 74, 3151, doi: 10.1063/1.1570949, 2003.

Wennberg, P., Hanisco, T., Jaegle, L., Jacob, D., Hintsa, E., Lanzendorf, E., Anderson, J., Gao, R., Keim, E., Donnelly, S., et al.: Hydrogen radicals, nitrogen radicals, and the production of $\mathrm{O}_{3}$ in the upper troposphere, Science, 279, 49, doi: 10.1126/science.279.5347.49, 1998 .

Williams, D.: Calibration in Air Monitoring, ASTM STP, 598, 183 197, 1976.

Williams, J.: Organic trace gases in the atmosphere: An overview, Environ. Chem., 1, 125-136, 2004.

Wyche, K. P., Blake, R. S., Ellis, A. M., Monks, P. S., Brauers, T., Koppmann, R., and Apel, E. C.: Technical Note: Performance of Chemical Ionization Reaction Time-of-Flight Mass Spectrometry (CIR-TOF-MS) for the measurement of atmospherically significant oxygenated volatile organic compounds, Atmos. Chem. Phys., 7, 609-620, doi:10.5194/acp-7-609-2007, 2007.

Xiuli, Z., Weidong, Z., Xinmin, H., Huifeng, Z., Zeting, Z., and Jianchun, Z.: Mathematical Model of Gas Permeation Through PTFE Porous Membrane and the Effect of Membrane Pore Structure, Chinese J. Chem. Eng., 11, 383-387 2003.

Yi-Yan, N., Felder, R., and Koros, W.: Selective permeation of hydrocarbon gases in poly (tetrafluoroethylene) and poly (fluoroethylene-propylene) copolymer, J. Appl. Polym. Sci., 25, 1755-1774, 1980. 